\title{
Prognostic factors for survival among patients with primary bone sarcomas of small bones
}

This article was published in the following Dove Press journal:

Cancer Management and Research

\section{Zhan Wang, ${ }^{1}, *$ Shu $\mathrm{Li}^{2, *}$ Yong Li,' Nong Lin,' Xin Huang,' Meng Liu,' Weibo Pan, ' Xiaobo Yan,' Lingling Sun,' Hengyuan, Li,' Binghao Li,' Hao Qu, 'Yan Wu,' Peng Lin,' Zhaoming $\mathrm{Ye}^{\prime}$}

'Department of Orthopaedics, The Second Affiliated Hospital of Zhejiang University School of Medicine, Centre for Orthopaedic Research, Orthopedics Research Institute of Zhejiang University, Hangzhou, China; ${ }^{2}$ Key Laboratory of Cancer Prevention and Intervention, Key Laboratory of Molecular Biology in Medical Sciences, National Ministry of Education, Department of Hematology, The Second Affiliated Hospital, Zhejiang University School of Medicine, Cancer Institute, Hangzhou, China

*These authors contributed equally to this work
Correspondence: Zhaoming Ye Department of Orthopaedics, The Second Affiliated Hospital of Zhejiang University School of Medicine, Centre for Orthopaedic Research, Orthopedics Research Institute of Zhejiang University, Zhejiang University, 88 Jiefang Road, Hangzhou, Zhejiang 310000, China Email yezhaoming@zju.edu.cn
Background: Primary bone sarcomas of the hands or feet are rare lesions and poorly documented. Moreover, the prognostic determinants of bone sarcomas of the hands or feet have not been reported.

Materials and methods: The Surveillance, Epidemiology, and End Results (SEER) program database was used to screen patients with bone sarcomas of the hands or feet from 1973 to 2013, with attention paid to chondrosarcoma, Ewing sarcoma, and osteosarcoma. The prognostic values of overall survival (OS) and cancer-specific survival (CSS) were assessed using Cox proportional hazards regression model with univariate and multivariate analyses. The Kaplan-Meier method was used to obtain OS and CSS curves.

Results: A total of 457 cases were selected from the SEER database. Chondrosarcoma was the most common form of lesion in hands or feet or both, followed by Ewing sarcoma and osteosarcoma. The 5- and 10 -year OS rates of the entire group were $75.7 \%$ and $66.1 \%$, respectively. The 5- and 10-year CSS rates were $78.7 \%$ and $73.7 \%$, respectively. Multivariate analysis revealed that age under 40 years, localized stage, low grade, surgical treatment, and first primary tumor were associated with improved OS, and decade of diagnosis, stage, grade, and surgery were independent predictors of CSS. However, no significant differences were observed in OS and CSS among patients with different primary tumor locations and tumor subtypes. Additionally, the most significant prognostic factor was whether metastasis had occurred at the time of initial diagnosis. Conclusion: Among patients with primary bone sarcomas of the hands or feet, younger age ( $<40$ years), localized stage, low grade, surgical treatment, and first primary tumor are favorable factors for prolonging survival.

Keywords: chondrosarcoma, Ewing sarcoma, osteosarcoma, short bone, prognosis

\section{Introduction}

Primary bone sarcomas are very rare and unfamiliar entities in the hands or feet; these tumors include chondrosarcoma, Ewing sarcoma, and osteosarcoma. ${ }^{1}$ Many studies reported that chondrosarcomas were the most frequent malignant bone tumors in the hands or feet. ${ }^{2,3}$ The most common sites of chondrosarcoma include the pelvis, proximal femur, and humerus; however, the small bones of the lower $(2.2 \%)$ and upper $(2.1 \%)$ extremities are very rare sites for chondrosarcoma. ${ }^{4}$ Ewing sarcoma is the second most common primary bone tumor in children and adolescents. The bones of the hands $(1.4 \%)$ or feet $(4 \%)$ are also uncommon sites for Ewing sarcoma. Osteosarcoma is the most common primary bone malignancy in children and young adults, primarily occurring in the metaphysis of long bones. The incidence of osteosarcoma in the short bones is extremely low $(\sim 0.9 \%){ }^{3}$ Due to the rarity of bone sarcomas at these sites, 
case reports and case series are the most common reports. Moreover, most of these focused on the epidemiologic data and put less value on prognosis.

To obtain insight into primary bone sarcomas of the hands and feet, the Surveillance, Epidemiology, and End Results (SEER) program database was used to screen patients with bone sarcomas of the hands or feet from 1973 to 2013, with attention paid to chondrosarcoma, Ewing sarcoma, and osteosarcoma. The emphasis was mainly placed on determining prognostic factors for overall survival (OS) and cancerspecific survival (CSS) in these patients.

\section{Materials and methods Patient population}

The cohort consisted of patients diagnosed with chondrosarcoma, Ewing sarcoma, and osteosarcoma of the short bones from 1973 to 2013. Patient data were obtained using the case-listing session procedure in the SEER program of the National Cancer Institute. The SEER database holds only anonymized data, which are freely available. This study was performed in accordance with standard guidelines and was approved by the Ethics Committee of the Second Affiliated Hospital, School of Medicine, Zhejiang University.

All primary tumors that originated in the short bones were identified using the lesion number $\mathrm{C} 40.1$ (short bones of upper limb and associated joints) and C40.3 (short bones of lower limb and associated joints). The International Classification of Diseases for Oncology, 3rd edition (ICD-O-3) was then used to identify patients with chondrosarcoma (ICDO-3 codes 9180, 9220, 9221, 9231, 9240, 9242, and 9243), Ewing sarcoma (ICD-O-3 code 9260), and osteosarcoma (ICD-O-3 codes 9180-9187 and 9192-9195). All patients were diagnosed by histologic confirmation either from biopsy or surgical pathology. Patients who were diagnosed from only clinical presentation, radiography, autopsy, or death records were excluded. Data extracted from the SEER database included patient demographics, stage at diagnosis, tumor grade, tumor type, tumor sequence, cause of death, year of diagnosis, surgical treatment, and survival time.

\section{Statistical methods}

Statistical analyses were performed using the SPSS statistical package version 21.0 and Microsoft Excel 2016. OS was defined as the time from diagnosis to death from any cause, and CSS was defined as the time from diagnosis to death specific to the cancer-related diagnosis. Descriptive epidemiologic data were calculated for all variables. OS and CSS curves were calculated using the Kaplan-Meier method. Observations were censored if the patient was alive at the time of the last follow-up. The effects of demographic variables, tumor characteristics, and treatment variables were compared using log-rank tests for categorical values. The Cox proportional hazards regression model was used to determine the independent prognostic factor for OS and CSS using univariate and multivariate analyses. The hazard ratios (HRs) with corresponding 95\% CIs were used to show the effect of factors on OS and CSS. Differences were deemed statistically significant if $p<0.05$.

\section{Results}

In total, 457 patients were eligible for the study, including 245 patients with chondrosarcoma, 115 patients with osteosarcoma, and 97 patients with Ewing sarcoma of hands or feet. Chondrosarcoma was the most common type in hands, feet, or both. Demographically, $53.4 \%$ and $46.6 \%$ of patients were male and female, respectively. Most patients (84.2\%) were white. The mean age at diagnosis was 41.9 years, and more than half of the patients $(62.4 \%)$ were born in or after the year 2000 . Histologically, $42.2 \%$ of cases were low grade, $22.5 \%$ were high grade, and $35.2 \%$ were an unknown tumor grade. Information regarding the extent of disease was available in most cases $(92.3 \%)$, and the majority presented as locally invasive disease (46.2\%). Forty-eight patients (10.5\%) had developed metastasis at presentation. Most patients were diagnosed with first malignant primary tumors (93.7\%). After diagnosis, $88 \%$ of patients underwent surgical treatment. A total of 176 patients (38.5\%) died; among these, 95 died of the tumor itself (cancer-specific death). The OS rates of the entire cohort at 5 and 10 years were $75.7 \%$ and $66.1 \%$, respectively. The CSS rates at 5 and 10 years were $78.7 \%$ and $73.7 \%$, respectively. The 5- and 10-year OS rates for patients with malignant osseous foot tumors were $72.2 \%$ and $63.7 \%$, and the respective 5- and 10-year CSS rates were $74.1 \%$ and $68.0 \%$. For patients with malignant osseous hand tumors, the OS rates were $81.2 \%$ and $70.9 \%$ and the CSS rates were $86.3 \%$ and $83.4 \%$, respectively (Table 1 ).

Univariate survival analysis revealed that older age (age $>40$ years) was significantly associated with a worse OS $(\mathrm{HR}=1.618, p=0.002$; Table 2; Figure 1A) but not with a worse CSS (HR=0.797, $p=0.287$; Table 3 ). Similarly, gender was associated with significant differences in OS (male vs. female $\mathrm{HR}=0.733, p=0.042$; Table 2) but not in CSS (male vs. female $\mathrm{HR}=1.136, p=0.544$; Table 3 ). A more recent year of diagnosis was associated with improved CSS (1990s vs. $1970 \mathrm{~s}, \mathrm{HR}=0.287, p=0.002 ; \geq 2000 \mathrm{~s}$ vs. $1970 \mathrm{~s}, \mathrm{HR}=0.332$, $p=0.002$; Table 3 ; Figure $2 \mathrm{~A})$ but not with $\mathrm{OS}(p>0.05$; 
Table I Clinical characteristics of patients with osteosarcoma, chondrosarcoma, and Ewing sarcoma of short bones

\begin{tabular}{|c|c|c|c|}
\hline \multirow[t]{2}{*}{ Variables } & \multicolumn{3}{|l|}{ Number (\%) } \\
\hline & $\begin{array}{l}\text { Hands and } \\
\text { foot }\end{array}$ & Hand & Foot \\
\hline Mean age (years) & 41.9 & 49.6 & 37.5 \\
\hline \multicolumn{4}{|l|}{ Age (years) } \\
\hline$<40$ & $227(49.7)$ & $58(35.6)$ & $169(57.5)$ \\
\hline$\geq 40$ & $230(50.3)$ & $105(64.4)$ & $125(42.5)$ \\
\hline \multicolumn{4}{|l|}{ Gender } \\
\hline Female & $213(46.6)$ & $85(52.1)$ & $128(43.5)$ \\
\hline Male & $244(53.4)$ & $78(47.9)$ & $166(56.5)$ \\
\hline \multicolumn{4}{|l|}{ Decade of diagnosis } \\
\hline 1970 s & $36(7.9)$ & $14(8.6)$ & $22(7.5)$ \\
\hline $1980 \mathrm{~s}$ & $58(12.7)$ & $21(12.9)$ & $37(12.6)$ \\
\hline $1990 \mathrm{~s}$ & $78(17.1)$ & $33(20.2)$ & $45(15.3)$ \\
\hline$\geq 2000 \mathrm{~s}^{\mathrm{a}}$ & $285(62.4)$ & $95(58.3)$ & $190(64.6)$ \\
\hline \multicolumn{4}{|l|}{ Race } \\
\hline White & $385(84.2)$ & I43 (87.7) & $242(82.3)$ \\
\hline Black & $39(8.5)$ & $9(5.5)$ & $30(10.2)$ \\
\hline Other & $33(7.3)$ & II (6.7) & $22(7.5)$ \\
\hline \multicolumn{4}{|l|}{ Location } \\
\hline Upper & $163(35.7)$ & $163(100)$ & - \\
\hline Lower & $294(64.3)$ & - & $294(100)$ \\
\hline \multicolumn{4}{|l|}{ Stage } \\
\hline Localized & $211(46.2)$ & $87(53.4)$ & $124(42.2)$ \\
\hline Regional & $163(35.7)$ & $63(38.7)$ & $100(34.0)$ \\
\hline Distant & $48(10.5)$ & $5(3.1)$ & $43(14.6)$ \\
\hline Unstaged & $35(7.7)$ & $8(4.9)$ & $27(9.2)$ \\
\hline \multicolumn{4}{|l|}{ Tumor grade ${ }^{b}$} \\
\hline Low & $193(42.2)$ & $93(57.1)$ & $100(34.0)$ \\
\hline High & $103(22.5)$ & $22(13.5)$ & $81(27.6)$ \\
\hline Unknown & $161(35.2)$ & $48(29.4)$ & $113(38.4)$ \\
\hline \multicolumn{4}{|l|}{ Tumor type } \\
\hline Chondrosarcoma & $245(53.6)$ & $114(69.9)$ & I3I (44.6) \\
\hline Osteosarcoma & $115(25.2)$ & $29(17.8)$ & $86(29.3)$ \\
\hline Ewing sarcoma & $97(21.2)$ & $20(12.3)$ & $77(26.2)$ \\
\hline \multicolumn{4}{|l|}{ Surgery } \\
\hline Yes & $402(88)$ & I5I (92.6) & $25 I(85.4)$ \\
\hline No & $55(12)$ & $12(7.4)$ & $43(14.6)$ \\
\hline \multicolumn{4}{|l|}{ Tumor sequence } \\
\hline First & $428(93.7)$ & 149 (9|.4) & 279 (94.9) \\
\hline$\geq$ Second & $29(6.3)$ & $14(8.6)$ & $15(5.1)$ \\
\hline \multicolumn{4}{|l|}{ Dead } \\
\hline Yes & $176(38.5)$ & $63(38.7)$ & $113(38.4)$ \\
\hline No & $281(61.5)$ & $100(61.3)$ & $181(61.6)$ \\
\hline 5-year OS rate & $75.7 \%$ & $81.2 \%$ & $72.2 \%$ \\
\hline 5-year CSS rate & $78.7 \%$ & $86.3 \%$ & $74.1 \%$ \\
\hline 10-year OS rate & $66.1 \%$ & $70.9 \%$ & $63.7 \%$ \\
\hline 10-year CSS rate & $73.7 \%$ & $83.4 \%$ & $68.0 \%$ \\
\hline
\end{tabular}

Notes: 2000-2013; blow: Grade I (well differentiated) and Grade II (moderately differentiated); high: Grade III (poorly differentiated) and Grade IV (undifferentiated anaplastic).

Abbreviations: CSS, cancer-specific survival; OS, overall survival.

Table 2). For both OS and CSS, race showed no significant effect on survival ( $p>0.05$; Tables 2 and 3 ). Compared with patients with bone sarcomas of the hands, patients with sarcomas of the feet had worse CSS (HR=1.912, $p=0.010$;
Table 3 ) but not OS ( $p>0.05$; Table 2$)$. There was a significant difference in both OS and CSS based on the extent of disease at presentation (OS: regional vs. localized, $\mathrm{HR}=1.504$, $p=0.024$; and distant vs. localized, HR $=5.722, p=0.000$; CSS: regional vs. localized, $\mathrm{HR}=2.100, p=0.010$; and distant vs. localized, $\mathrm{HR}=12.902, p=0.000$; Tables 2 and 3; Figures 1B and $2 \mathrm{~B}$ ). Univariate analysis indicated that tumor grade was an important prognostic factor for both OS and CSS (both $p=0.000$; Tables 2 and 3; Figures $1 \mathrm{C}$ and $2 \mathrm{C}$ ), with high tumor grade portending a worse prognosis. Compared with chondrosarcoma, the prognosis of patients with Ewing sarcoma was much worse in terms of OS (Ewing sarcoma vs. chondrosarcoma, $\mathrm{HR}=1.758, p=0.002$; Table 2 ) and CSS (Ewing sarcoma vs. chondrosarcoma, $\mathrm{HR}=4.550, p=0.000$; Table 3). In terms of treatment, patients who did not receive surgical treatment had worse OS and CSS than patients who underwent surgery $(\mathrm{HR}=2.258, p=0.000$ and $\mathrm{HR}=3.614$, $p=0.000$, respectively; Tables 2 and 3; Figures 1D and 2D). Additionally, there were significant differences in OS (second or more vs. first, $\mathrm{HR}=1.879, p=0.020$; Table 2; Figure 1E) but not CSS ( $p=0.214$; Table 3 ) based on tumor sequence.

On multivariate analysis for all patients (Table 2), age at diagnosis $(\mathrm{HR}=2.418 ; 95 \% \mathrm{CI}, 1.635-3.574 ; p=0.000)$, stage (regional vs. localized, HR $=1.480,95 \%$ CI, 1.034 2.119, $p=0.032$; distant vs. localized, $\mathrm{HR}=3.839,95 \% \mathrm{CI}$, $2.375-6.205, p=0.000)$, tumor grade $(\mathrm{HR}=1.643 ; 95 \%$ CI, 1.025-2.636; $p=0.039)$, surgery $(\mathrm{HR}=1.792 ; 95 \% \mathrm{CI}$, $1.139-2.818 ; p=0.012)$, and tumor sequence $(\mathrm{HR}=2.284$; $95 \%$ CI, $1.304-4.000 ; p=0.004)$ were independent predictors of OS. The results of multivariate analysis of the parameters that influence CSS are presented in Table 3. Decade of diagnosis $(1980$ s vs. $1970 \mathrm{~s}, \mathrm{HR}=0.382,95 \% \mathrm{CI}, 0.168-0.866$, $p=0.021 ; 1990$ s vs. $1970 \mathrm{~s}, \mathrm{HR}=0.171,95 \% \mathrm{CI}, 0.069-0.424$, $p=0.000 ; \geq 2000$ s vs. 1970 s, HR $=0.269,95 \%$ CI, $0.128-0.563$, $p=0.000$ ), stage (distant vs. localized, HR=7.040;95\% CI, 3.708-13.364; $p=0.000)$, tumor grade $(\mathrm{HR}=3.385 ; 95 \% \mathrm{CI}$, $1.523-7.523 ; p=0.003)$, and surgery $(\mathrm{HR}=1.890 ; 95 \% \mathrm{CI}$, $1.133-3.151 ; p=0.015)$ were independent prognostic factors for CSS. Moreover, multivariate analysis showed no statistically significant difference among primary tumor location and tumor type.

\section{Discussion}

Bone sarcomas of small bones of the hands or feet are rare malignancies, and have the potential for both local aggressive performance and distant metastasis. Ogose et $\mathrm{al}^{5}$ found that chondrosarcoma of the small bones of the hands or feet had the potential for metastasis and high mortality. Therefore, 
Table 2 Univariate and multivariate analyses for OS for patients identified in the SEER Program database from 1973 to 2013

\begin{tabular}{|c|c|c|c|c|}
\hline \multirow[t]{2}{*}{ Variables } & \multicolumn{2}{|l|}{ Univariate analysis } & \multicolumn{2}{|l|}{ Multivariate analysis } \\
\hline & Hazard ratio $(95 \% \mathrm{Cl})$ & $\overline{p \text {-value }}$ & Hazard ratio $(95 \% \mathrm{Cl})$ & $\overline{p \text {-value }}$ \\
\hline \multicolumn{5}{|l|}{ Age (years) } \\
\hline$<40$ & 1 & & 1 & \\
\hline$\geq 40$ & $1.618(1.193-2.194)$ & $0.002^{* *}$ & $2.418(1.635-3.574)$ & $0.000^{* * *}$ \\
\hline \multicolumn{5}{|l|}{ Gender } \\
\hline Female & $\mathrm{I}$ & & 1 & \\
\hline Male & $0.733(0.543-0.989)$ & $0.042^{*}$ & $0.806(0.586-1.106)$ & 0.182 \\
\hline \multicolumn{5}{|l|}{ Decade of diagnosis } \\
\hline 1970s & 1 & & & \\
\hline $1980 \mathrm{~s}$ & $0.897(0.543-1.480)$ & 0.670 & - & - \\
\hline $1990 \mathrm{~s}$ & $0.743(0.443-1.244)$ & 0.258 & - & - \\
\hline$\geq 2000 \mathrm{~s}$ & $0.722(0.449-1.164)$ & 0.181 & - & - \\
\hline \multicolumn{5}{|l|}{ Race } \\
\hline White & I & & & \\
\hline Black & $0.897(0.5 \mid 8-1.553)$ & 0.697 & - & - \\
\hline Other & $1.239(0.702-2.187)$ & 0.459 & - & - \\
\hline \multicolumn{5}{|l|}{ Location } \\
\hline Upper & 1 & & - & - \\
\hline Lower & $1.142(0.838-1.556)$ & 0.400 & - & - \\
\hline \multicolumn{5}{|l|}{ Stage } \\
\hline Localized & I & & I & \\
\hline Regional & $1.504(1.056-2.143)$ & 0.024 & $1.480(1.034-2.119)$ & $0.032 *$ \\
\hline Distant & $5.722(3.782-8.659)$ & $0.000 * * *$ & $3.839(2.375-6.205)$ & $0.000 * * *$ \\
\hline Unstaged & $1.450(0.835-2.519)$ & 0.187 & $1.100(0.612-1.979)$ & 0.750 \\
\hline \multicolumn{5}{|l|}{ Tumor grade } \\
\hline Low & I & & I & \\
\hline High & $2.155(1.462-3.178)$ & $0.000 * * *$ & $1.643(1.025-2.636)$ & $0.039 *$ \\
\hline Unknown & 1.621 (1.139-2.307) & $0.007^{* *}$ & 1.491 (0.965-2.302) & 0.072 \\
\hline \multicolumn{5}{|l|}{ Tumor type } \\
\hline Chondrosarcoma & I & & 1 & \\
\hline Osteosarcoma & $1.250(0.870-1.798)$ & 0.228 & $\mathrm{I} .200(0.763-1.887)$ & 0.429 \\
\hline Ewing sarcoma & $1.758(1.224-2.526)$ & $0.002^{* *}$ & $1.723(0.994-2.986)$ & 0.053 \\
\hline \multicolumn{5}{|l|}{ Surgery } \\
\hline Yes & I & & I & \\
\hline No & $2.258(1.528-3.337)$ & $0.000^{* * * *}$ & $1.792(1.139-2.818)$ & $0.012^{*}$ \\
\hline \multicolumn{5}{|l|}{ Tumor sequence } \\
\hline First & I & & I & \\
\hline$\geq$ Second & $1.879(1.103-3.201)$ & $0.020 *$ & $2.284(1.304-4.000)$ & $0.004^{* *}$ \\
\hline
\end{tabular}

Note: ${ }^{*} p<0.05, * * p<0.01, * * * p<0.000$.

Abbreviations: OS, overall survival; SEER, Surveillance, Epidemiology, and End Results.

equal attention should be paid to the prognosis of patients with bone sarcomas of both long and short bones. Previous studies mostly reported on soft-tissue sarcomas of the hands or feet rather than osseous malignancies. ${ }^{6-8}$ Recently, Yang et $\mathrm{al}^{9}$ documented the clinical features and incidence of malignant osseous foot tumors and evaluated the clinical course and outcomes of the malignancy. Henderson et a ${ }^{10}$ retrospectively analyzed the clinical presentation, radiographic features, and treatment choice of malignant osseous hand tumors. However, these studies had small heterogeneous cohorts, and the prognostic results of those patients were not analyzed. To our knowledge, the current study is the first to report the factors that affect the prognostic factors that affect the survival of patients with primary malignant bone tumors of the hands or feet, which is often ignored by orthopedists. Furthermore, the study used multivariate regression analysis to identify possible prognostic factors for survival in those patients.

Although many case reports and case series reported bone sarcomas of the hands or feet, there was a lack of demographic knowledge information. Farzan et al ${ }^{11}$ reported 99 osseous tumors of the hands and only found two chondrosarcomas, one osteosarcoma, and one Ewing sarcoma involving the hand skeleton, suggesting that bone sarcomas of the small bones were rare. In the current study, we identified 457 cases of primary malignant bone tumors of the hands or feet based on the SEER database from 1973 to 2013. Chondrosarcoma 
A

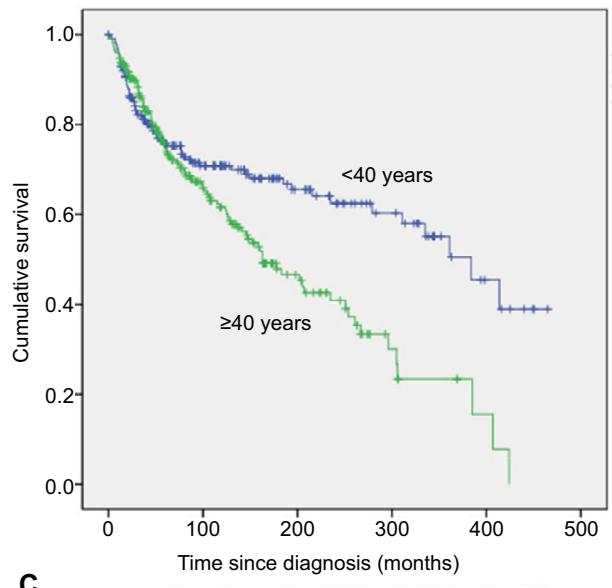

C

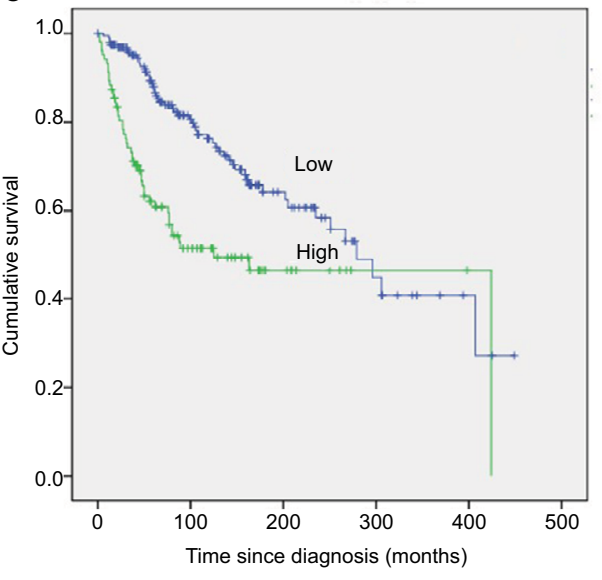

B

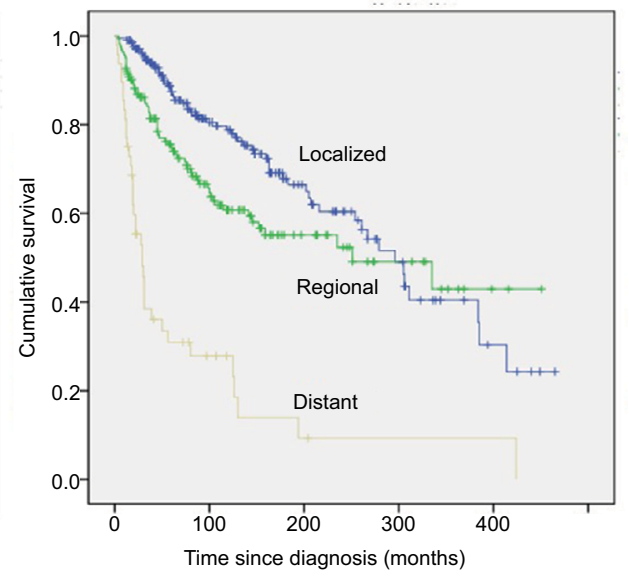

D

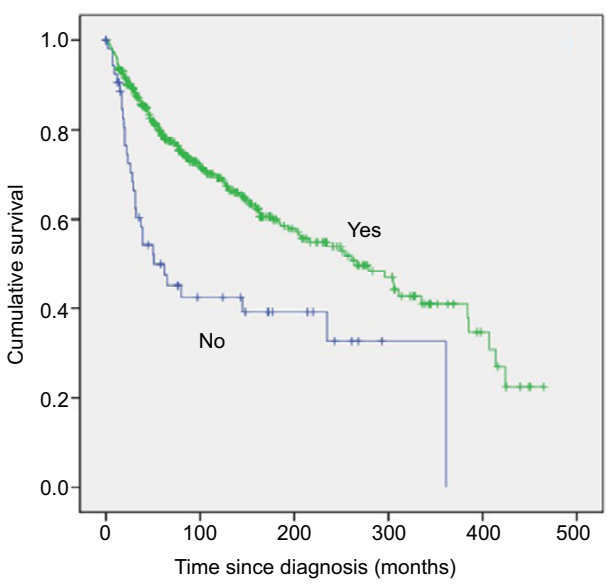

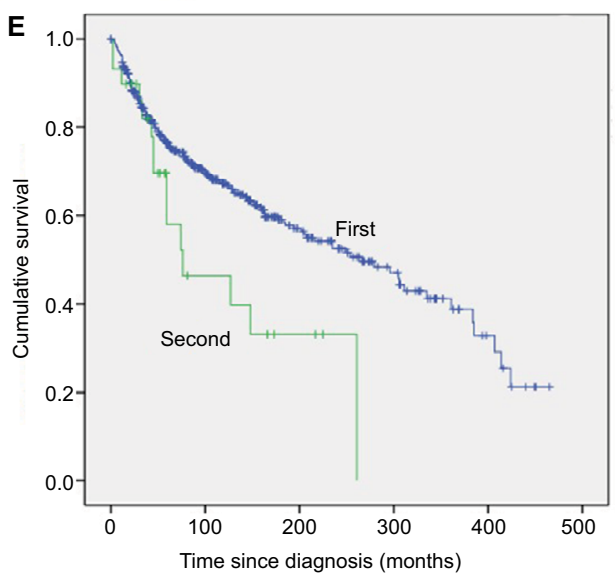

Figure I Kaplan-Meier estimated OS in patients with primary bone sarcomas of small bones of the hands and feet stratified by age (A), stage (B), tumor grade (C), surgery (D), and tumor sequence (E).

Abbreviation: OS, overall survival.

was the most common primary malignant bone tumor in the hands, feet, or both, followed by Ewing sarcoma and osteosarcoma; $69.9 \%$ of cases were chondrosarcoma. Murari et $\mathrm{al}^{2}$ found that the most common malignant neoplasm in the bones of the feet was chondrosarcoma, which accounted for $52.3 \%$ of malignant neoplasms and is similar to the current findings (44.6\%). Moreover, Saglık et $\mathrm{al}^{12}$ reported that the most common nonmetastatic malignant lesions of the bones in the hands were also chondrosarcomas $(n=6 / 16 ; 37.5 \%)$. However, Ewing sarcoma was the most common malignancy of the bones of the feet $(17 / 68 ; 25 \%)$ in a study by Bakotic and Huvos. ${ }^{13}$ Interestingly, the current study revealed that 48 $(10.5 \%)$ patients had metastatic disease at initial presentation and most of them $(n=43)$ were due to bone sarcomas in feet. 
Table 3 Univariate and multivariate analyses for CSS for patients identified in the SEER Program database from 1973 to 2013

\begin{tabular}{|c|c|c|c|c|}
\hline \multirow[t]{2}{*}{ Variables } & \multicolumn{2}{|l|}{ Univariate analysis } & \multicolumn{2}{|l|}{ Multivariate analysis } \\
\hline & Hazard ratio $(95 \% \mathrm{Cl})$ & $p$-value & Hazard ratio $(95 \% \mathrm{Cl})$ & p-value \\
\hline \multicolumn{5}{|l|}{ Age (years) } \\
\hline$<40$ & 1 & & - & \\
\hline$\geq 40$ & $0.797(0.525-1.210)$ & 0.287 & - & - \\
\hline \multicolumn{5}{|l|}{ Gender } \\
\hline Female & I & & - & \\
\hline Male & $1.136(0.752-1.717)$ & 0.544 & - & - \\
\hline \multicolumn{5}{|l|}{ Decade of diagnosis } \\
\hline $1970 \mathrm{~s}$ & I & & 1 & \\
\hline $1980 \mathrm{~s}$ & $0.528(0.244-1.145)$ & 0.106 & $0.382(0.168-0.866)$ & $0.021 *$ \\
\hline $1990 \mathrm{~s}$ & $0.287(0.128-0.642)$ & $0.002^{* *}$ & $0.17 I(0.069-0.424)$ & $0.000 * * *$ \\
\hline$\geq 2000$ s & $0.332(0.167-0.664)$ & $0.002^{* *}$ & $0.269(0.128-0.563)$ & $0.000 * * *$ \\
\hline \multicolumn{5}{|l|}{ Race } \\
\hline White & I & & - & \\
\hline Black & $0.928(0.448-1.921)$ & 0.840 & - & - \\
\hline Other & I.277(0.6I7-2.645) & 0.510 & - & - \\
\hline \multicolumn{5}{|l|}{ Location } \\
\hline Upper & I & & 1 & \\
\hline Lower & $1.912(1.167-3.135)$ & $0.010^{*}$ & $1.000(0.586-1.709)$ & 0.999 \\
\hline \multicolumn{5}{|l|}{ Stage } \\
\hline Localized & I & & 1 & \\
\hline Regional & $2.100(1.193-3.699)$ & $0.010^{*}$ & $1.646(0.922-2.938)$ & 0.092 \\
\hline Distant & $12.902(7.333-22.699)$ & $0.000 * * *$ & $7.040(3.708-13.364)$ & $0.000 * * *$ \\
\hline Unstaged & $3.305(1.612-6.778)$ & $0.00 I^{* *}$ & $2.214(0.998-4.910)$ & 0.050 \\
\hline \multicolumn{5}{|l|}{ Tumor grade } \\
\hline Low & 1 & & 1 & \\
\hline High & $6.362(3.228-12.538)$ & $0.000 * * *$ & $3.385(1.523-7.523)$ & $0.003 * *$ \\
\hline Unknown & $5.603(2.912-10.782)$ & $0.000 * * *$ & $2.080(0.919-4.709)$ & 0.079 \\
\hline \multicolumn{5}{|l|}{ Tumor type } \\
\hline Chondrosarcoma & I & & 1 & \\
\hline Osteosarcoma & $2.879(1.667-4.975)$ & $0.000 * * *$ & $1.347(0.726-2.501)$ & 0.345 \\
\hline Ewing sarcoma & $4.550(2.7 \mid 4-7.626)$ & $0.000 * * *$ & $1.313(0.672-2.567)$ & 0.425 \\
\hline \multicolumn{5}{|l|}{ Surgery } \\
\hline Yes & I & & 1 & \\
\hline No & $3.614(2.332-5.603)$ & $0.000 * * *$ & $1.890(1.133-3.151)$ & $0.015 *$ \\
\hline \multicolumn{5}{|l|}{ Tumor sequence } \\
\hline First & I & & - & - \\
\hline$\geq$ Second & $0.047(0.000-5.838)$ & 0.214 & - & \\
\hline
\end{tabular}

Note: ${ }^{*} p<0.05, * * p<0.01, * * * p<0.000$.

Abbreviations: CSS, cancer-specific survival; SEER, Surveillance, Epidemiology, and End Results.

No gender predilection was found both in either the hand or foot cohort. As the year at diagnosis increased, the number of patients in the series also increased. Moreover, the age range of patients in the cohort was very wide (from 1 to 102 years old). Therefore, it is important to suspect short bone sarcomas in patients of any age to reduce the risk of a delayed diagnosis. On average, patients presenting with bone sarcomas of the hands were older than those of the feet.

Most studies on bone sarcoma and survival primarily consisted of patients with appendicular or pelvic or spine disease. In general, the outcome among patients with sarcomas involving the pelvic bones or spine is much poorer than those with appendicular disease. ${ }^{14-17}$ Jawad et al ${ }^{18}$ found that the 5-year OS of all patients with pelvic sarcomas was $47 \%$. Similarly, Mukherjee et a ${ }^{14}$ reported that for all patients with sarcomas in the spine, the estimated 5- and 10-year OS rates were $41 \%$ and $34 \%$, respectively. However, the outcome and prognosis of patients with sarcomas of the hands or feet have not been reported frequently because of its rarity. Bishop et al $^{8}$ evaluated 85 patients with soft-tissue sarcomas of the hands or feet and found that the 5- and 10-year OS rates were $89 \%$ and $77 \%$, respectively. In the current study, the OS for osseous sarcomas of the hands or feet was $75.7 \%$ and $66.1 \%$ at 5 and 10 years, respectively, suggesting that 

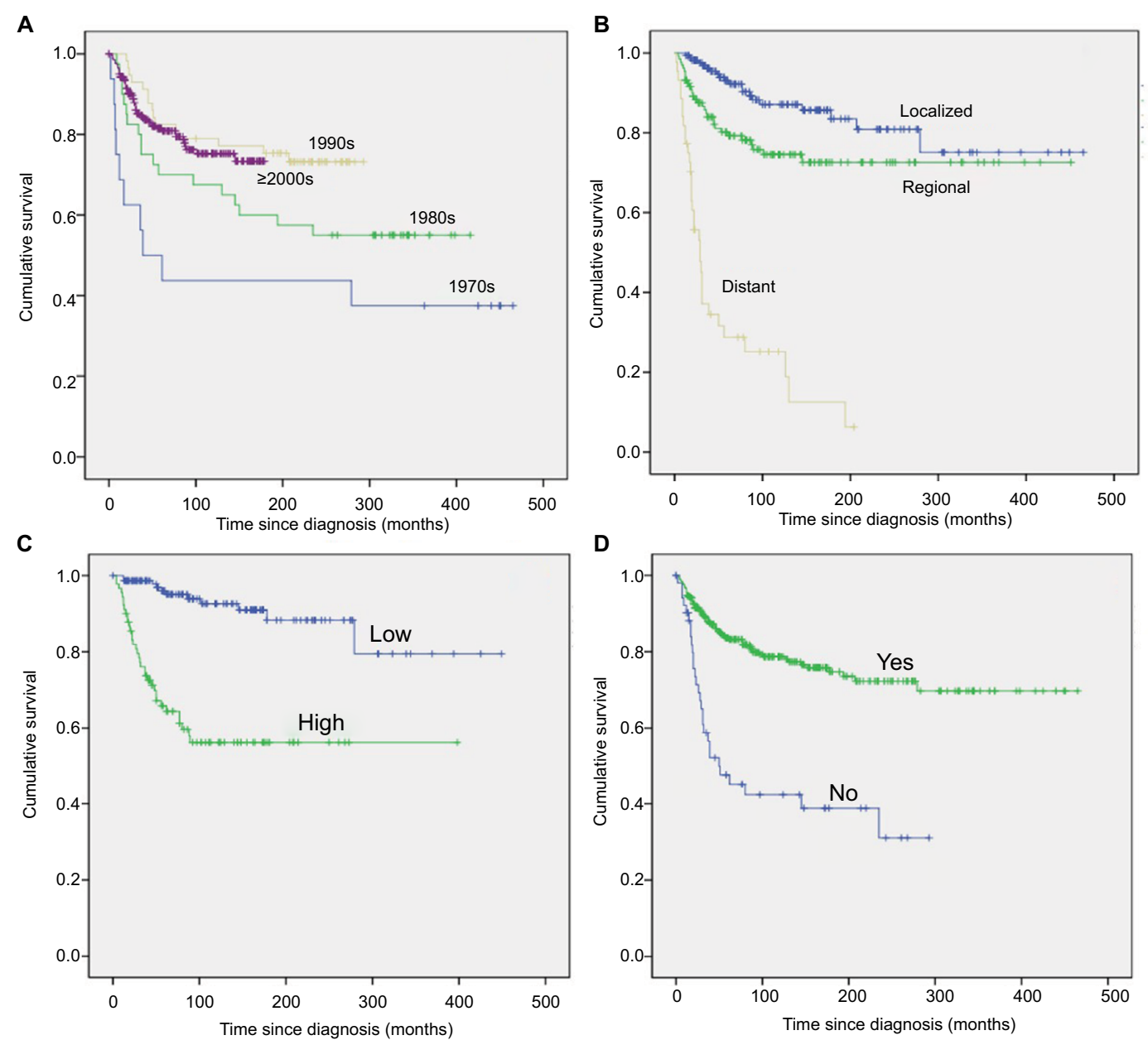

Figure 2 Kaplan-Meier survival analyses illustrating CSS in patients with primary bone sarcomas of small bones of the hands and feet based on decade of diagnosis (A), stage (B), tumor grade (C), and surgery (D).

Abbreviation: CSS, cancer-specific survival.

the prognosis of these patients may be poorer than the OS of those with soft-tissue sarcomas. More studies are needed to confirm it. In general, the prognosis of patients with bone sarcoma of the small bones appears to be more favorable than that of patients with disease affecting the long bones, who have an estimated 5 -year survival ranging from $45 \%$ to $75 \% .{ }^{19}$ Additionally, the current study showed that the 5- and 10 -year OS rates for patients with malignant osseous foot tumors were $72.2 \%$ and $63.7 \%$ and the 5 - and 10 -year CSS rates were $74.1 \%$ and $68.0 \%$, respectively. These outcomes were poorer than those of patients with malignant osseous hand tumors, whose OS rates were $81.2 \%$ and $70.9 \%$ and CSS rates were $86.3 \%$ and $83.4 \%$, respectively, at the same time points.

In terms of prognostic determinants, both univariate and multivariate analyses showed that age $>40$ years was associated with worse OS but not worse CSS. Mirabello et $\mathrm{al}^{20}$ also revealed that the survival rates for osteosarcomas were highest in the youngest age group, and lowest in elderly patients. For both OS and CSS, race was not associated with significant differences in survival. The current study noted that female gender was associated with a reduction in OS. However, gender was not an independent prognostic indicator of either OS or CSS. In addition, a more recent year of diagnosis was associated with better CSS but not OS, suggesting that the treatment of bone sarcomas in the hands or feet has improved significantly. Adjuvant therapy such as chemotherapy and radiation and the progress of multimodality imaging such as magnetic resonance imaging may be the contributed factors. ${ }^{8}$ The current multivariate survival analysis revealed that tumor location was not an independent prognostic indicator of either OS or CSS, suggesting that bone sarcomas in the hands or feet could be reported together for further analyses. Ewing sarcoma was adversely associated with CSS, but the significance was lost on multivariate analysis. Although tumor type was not an independent prognostic indicator for 
OS or CSS, a trend of decreased OS and CSS was observed for patients with Ewing sarcoma or osteosarcoma compared with those with chondrosarcoma. In addition, tumor sequence was an independent prognostic indicator of OS but not CSS, suggesting that patients with second or more primary bone sarcomas in their hands or feet may have a worse prognosis than those with a first primary tumor.

Stage, grade, and surgery have been previously recognized as predictors of survival in patients with malignant tumors. ${ }^{21-23}$ Similarly, these three factors were independent predictors of OS and CSS in the current study. Patients with metastatic disease at initial presentation have a poorer prognosis than those with localized disease. Furthermore, metastasis at diagnosis was the greatest indicator of both OS $(\mathrm{HR}=3.839 ;$ 95\% CI, 2.375-6.205) and CSS $(\mathrm{HR}=7.040 ; 95 \%$ CI, 3.708-13.364). Survival analysis using Kaplan-Meier curves (Figures 1B and 2B) revealed that the 5-year OS and CSS rates were $30.9 \%$ and $28.7 \%$, respectively. Bone sarcomas are highly metastatic tumors. ${ }^{15,24,25}$ Many studies suggested that pulmonary metastasectomy for sarcomas may confer better survival. ${ }^{26-28}$ Therefore, surgical removal of the primary tumor together with all clinically evident metastatic disease should be addressed and may be beneficial for prolonging survival in patients with bone sarcomas of the hands or feet and metastasis at diagnosis. Surgery treatment for patients with bone sarcomas of the hands or feet usually included amputation, wide resection, and combined modality therapy such as radiotherapy and chemotherapy. ${ }^{29}$ Yang et $\mathrm{al}^{9}$ reported that most of the patients with primary malignant bone tumors of the feet received surgical amputation, regardless of tumor histology or site and achieved excellent outcomes. Additionally, they thought that amputation was an appropriate management option for patients who had undergone previous accidental excisions. Careful staging, precise grading, and appropriate treatment are critical for improving prognosis as the short bones are an uncommon site for chondrosarcoma, Ewing sarcoma, and osteosarcoma.

\section{Limitations}

The SEER program database does not gather information about local recurrence or metastasis during the follow-up, which may affect prognosis. Additionally, other known prognostic factors for cancer survival, such as surgical method and chemotherapy, are not available in this database, which may be the contributing factors. Further research is needed to confirm their prognostic value. Nevertheless, the SEER program database provides important insights into rare cancers such as bone sarcomas of the hands or feet.

\section{Conclusion}

This is the largest population-based study to describe the demographics and analyze the prognosis of patients with bone sarcomas in the hands or feet. The OS and CSS rates of all patients at 10 years were $66.1 \%$ and $73.7 \%$, respectively. Independent predictors of OS include age, stage, grade, surgery, and tumor sequence. The decade of diagnosis, stage, grade, and surgery were independent predictors of CSS. For all tumor types, the most important prognostic factor was whether metastasis had occurred at the time of initial diagnosis. The results of this study may allow orthopedists to better understand the features and outcomes of bone sarcomas in the hands or feet. It may also be helpful for patient health education and lay a solid foundation for future research.

\section{Acknowledgment}

This work was supported by the 2017 Zhejiang provincial medical and health science and technology project (Grant no. 2017KY392).

\section{Disclosure}

The authors report no conflicts of interest in this work.

\section{References}

1. Hsu CS, Hentz VR, Yao J. Tumours of the hand. Lancet Oncol. 2007;8:157-166.

2. Murari TM, Callaghan JJ, Berrey BH Jr, Sweet DE. Primary benign and malignant osseous neoplasms of the foot. Foot Ankle. 1989;10:68-80.

3. Anninga JK, Picci P, Fiocco M, et al. Osteosarcoma of the hands and feet: a distinct clinico-pathological subgroup. Virchows Arch. 2013;462:109-120.

4. Damron TA, Ward WG, Stewart A. Osteosarcoma, chondrosarcoma, and Ewing's sarcoma: National Cancer Data Base Report. Clin Orthop Relat Res. 2007;459:40-47.

5. Ogose A, Unni KK, Swee RG, May GK, Rowland CM, Sim FH. Chondrosarcoma of small bones of the hands and feet. Cancer. 1997;80:50-59.

6. Bakotic BW, Borkowski P. Primary soft-tissue neoplasms of the foot: the clinicopathologic features of 401 cases. J Foot Ankle Surg. 2001;40:28-35.

7. DeGroot H 3rd. Approach to the management of soft tissue tumors of the foot and ankle. Foot Ankle Spec. 2008;1:168-176.

8. Bishop AJ, Zagars GK, Moon BS, Lin PP, Lewis VO, Guadagnolo BA. Combined limb-sparing surgery and radiation therapy to treat sarcomas of the hands and feet: long-term cancer outcomes and morbidity. Int $J$ Radiat Oncol Biol Phys. 2015;92:1060-1068.

9. Yang P, Evans S, Bali N, et al. Malignant bone tumours of the foot. Ann $R$ Coll Surg Engl. 2017;99:568-572.

10. Henderson M, Neumeister MW, Bueno RA Jr. Hand tumors: II. Benign and malignant bone tumors of the hand. Plast Reconstr Surg. 2014;133:814e-821e.

11. Farzan M, Ahangar P, Mazoochy H, Ardakani MV. Osseous tumours of the hand: a review of 99 cases in 20 years. Arch Bone Jt Surg. 2013;1:68-73.

12. Saglik Y, Atalar H, Armangil M, Basarir K, Yildiz Y, Bilgin S. Management of tumors and tumor-like lesions of the hand: a review of 191 patients. Eklem Hastalik Cerrahisi. 2013;24:149-155. 
13. Bakotic B, Huvos AG. Tumors of the bones of the feet: the clinicopathologic features of 150 cases. J Foot Ankle Surg. 2001;40:277-286.

14. Mukherjee D, Chaichana KL, Gokaslan ZL, Aaronson O, Cheng JS, McGirt MJ. Survival of patients with malignant primary osseous spinal neoplasms: results from the Surveillance, Epidemiology, and End Results (SEER) database from 1973 to 2003. JNeurosurg Spine. 2011;14:143-150.

15. Kawai A, Healey JH, Boland PJ, Lin PP, Huvos AG, Meyers PA. Prognostic factors for patients with sarcomas of the pelvic bones. Cancer. 1998;82:851-859.

16. Wirbel RJ, Schulte M, Mutschler WE. Surgical treatment of pelvic sarcomas: oncologic and functional outcome. Clin Orthop Relat Res. 2001:190-205.

17. Shin KH, Rougraff BT, Simon MA. Oncologic outcomes of primary bone sarcomas of the pelvis. Clin Orthop Relat Res. 1994:207-217.

18. Jawad MU, Haleem AA, Scully SP. Malignant sarcoma of the pelvic bones: treatment outcomes and prognostic factors vary by histopathology. Cancer. 2011;117:1529-1541.

19. Colding-Rasmussen T, Thorn AP, Horstmann P, et al. Survival and prognostic factors at time of diagnosis in high-grade appendicular osteosarcoma: a 21 year single institution evaluation from east Denmark. Acta Oncol. 2018;57(3):420-425.

20. Mirabello L, Troisi RJ, Savage SA. Osteosarcoma incidence and survival rates from 1973 to 2004: data from the Surveillance, Epidemiology, and End Results Program. Cancer. 2009;115:1531-1543.
21. Arshi A, Sharim J, Park DY, et al. Chondrosarcoma of the osseous spine: an analysis of epidemiology, patient outcomes, and prognostic factors using the SEER registry from 1973 to 2012. Spine. 2017;42:644-652.

22. Arshi A, Sharim J, Park DY, et al. Prognostic determinants and treatment outcomes analysis of osteosarcoma and Ewing sarcoma of the spine. Spine J. 2017;17:645-655.

23. Strotman PK, Reif TJ, Kliethermes SA, Sandhu JK, Nystrom LM Dedifferentiated chondrosarcoma: a survival analysis of 159 cases from the SEER database (2001-2011). J Surg Oncol. 2017;116:252-257.

24. Angelini A, Ceci F. The role of (18)F-FDG PET/CT in the detection of osteosarcoma recurrence. Eur J Nucl Med Mol Imaging. 2017;44:1712-1720.

25. Iwamoto Y. Diagnosis and treatment of Ewing's sarcoma. Jpn J Clin Oncol. 2007;37:79-89.

26. Okiror L, Peleki A, Moffat D, et al. Survival following pulmonary metastasectomy for sarcoma. Thorac Cardiovasc Surg. 2016;64:146-149.

27. Meazza C, Scanagatta P. Metastatic osteosarcoma: a challenging multidisciplinary treatment. Expert Rev Anticancer Ther. 2016;16:543-556.

28. Pastorino U, Buyse M, Friedel G, et al. Long-term results of lung metastasectomy: prognostic analyses based on 5206 cases. $J$ Thorac Cardiovasc Surg. 1997;113:37-49.

29. Lacey SH, Danish EH, Thompson GH, Joyce MJ. Ewing sarcoma of the proximal phalanx of a finger. A case report. J Bone Joint Surg Am. 1987;69:931-934.
Cancer Management and Research

\section{Publish your work in this journal}

Cancer Management and Research is an international, peer-reviewed open access journal focusing on cancer research and the optimal use of preventative and integrated treatment interventions to achieve improved outcomes, enhanced survival and quality of life for the cancer patient. The manuscript management system is completely online and includes

\section{Dovepress}

a very quick and fair peer-review system, which is all easy to use. Visit http://www.dovepress.com/testimonials.php to read real quotes from published authors. 